\title{
Case of Heterotopic Pancreas Involving Stomach and Duodenum
}

\author{
Zubin Sharma*, Divya Sharma, Ravindra Sharma, Santosh Kumar Yadav
}

Department of Gastroenterology, Aditya Hospital, Rajasthan, India

DOI: $\underline{10.36348 / \mathrm{sjm} .2020 . \mathrm{v} 05 \mathrm{i} 03.004}$

| Received: 19.02.2020 | Accepted: 01.03.2020 | Published: 06.03.2020

*Corresponding author: Dr. Zubin Sharma

\section{Abstract}

Heterotopic pancreas is a rare condition with a probable incidence of 1 per 500 upper abdominal operations. Findings are incidental and are usually asymptomatic. Heterotopic pancreas is seen at different sites in the gastrointestinal tract. A 62 year old male presented with complaints of epigastric pain, nausea, vomiting and constipation since 3 months. The diagnosis of malignancy was based upon the findings of abdominal ultrasonography, CECTabdomen and Upper G.I. endoscopy.

Keywords: Heterotopic Pancreas Stomach Duodenum.

Copyright @ 2020: This is an open-access article distributed under the terms of the Creative Commons Attribution license which permits unrestricted use, distribution, and reproduction in any medium for non-commercial use (NonCommercial, or CC-BY-NC) provided the original author and source are credited.

\section{INTRODUCTION}

Defination- Heterotopic pancreas is presence of pancreatic tissue missing anatomical and vascular continuity with the main body of the pancreas [1-6].

It has a reporting incidence of $1 \%-14 \%$ on necropsy examination and has been observed in 1 in 400 upper abdominal operations $[1,2]$. HP is more often an incidental finding and its derivation is explained on the basis of embryology [1]. Here we report an unusual case of heterotopic pancreas misdiagnosed as malignancy in a 62 year old male.

\section{CASE REPORT}

A 62 year old male was come to our hospital with complaints of pain in epigastric region, nausea, vomiting and constipation since 3 months. He was nondiabetic, normotensive without any significant illness in the past.

Per abdominal examination revealed a firm, immobile, diffuse lump in the epigastric region. No organomegaly was appreciated. His cardiovascular, respiratory and central nervous system examination findings were with in normal limits. Investigations including blood count, liver function test and kidney function test were normal. His Ultrasound of abdomen showed features of grossly distented stomach with thickened pylorus and first part of duodenum, with enlargement of peripancreatic and paraaortic lymph nodes, with the largest being $1.2 \mathrm{~cm}$ in diameter. CECT showed an illdefined enlarging soft tissue mass involving pylorus and first part of duodenum along with enlarged perigastric and peripancreatic nodes.

Upper G.I. endoscopy showed a large submucosal mass with mucosal ulceration suggestive of malignancy was seen. Biopsy showed presence of pancreatic tissue, comprised of exocrine pancreas and cystically dilated ducts surrounded by connective tissue.

\section{DISCUSSION}

The first case of heterotopic pancreas was described by Jean schultz in 1729 and Klob provided histological confirmation of HP in 1859[1].

Heterotopic Pancreas can present at any age but most often happens to occur in the fifth and sixth decades of life, and have male predominance [3]. It often remains asymptomatic throughout the life but may cause symptoms including epigastric pain, upper G.I.bleed, gastric ulcer, gastric outlet obstruction and even pancreatitis $[1,6]$. Our patient was 62 years male who presented with epigastric pain, lump and with features of gastric outlet obstruction. The usual site of heterotopic pancreas is in the stomach in $28 \%-40 \%$ of cases, duodenum in $18 \%-22 \%$ and jejunum in $13 \%$ $20 \%$ of cases [1-6]. Lesion was located in the pylorus and first part of duodenum in this case. The classic endoscopic picture is that of a small, well circumscribed submucosal protrusion with a normal overlying mucosa. Many of the times it appears as a mass indistinguishable from adenomatous polyp or a polypoid carcinoma [5]; which was seen in this case on endoscopy. 
The clinical diagnosis of malignancy was rendered in this case based on the findings of $\mathrm{UsG}, \mathrm{Ct}$ scan and G.I. endoscopy, of a large mass involving the pylorus and first part of duodenum with mucosal ulceration and perigastric and peripancreatic lymphodenopathy.

Histologically the lesions are of three categories;

Type- 1 is pancreatic tissue comprised of ducts, acini and islets (most common).

Type- 2 there are few acini and many ducts,

Type 3 only ducts are seen. Smooth muscle is present throughout the lesions.3 biopsy via endoscopy showed heterotopic pancreas (type 2)

Clinical significance of Heterotopic pancreas lies in the fact that if it is often confused with benign and malignant gastric wall tumours and many pathologic process that may affect the normal pancreas may develop in the heterotopic pancreas as well including acute and chronic pancreatitis, cyst formation, cystic fibrosis and both benign and malignant neoplasms[5,6]. The symptomatic lesions require local excision and if heterotopic pancreas is found incidentally during surgery for any another condition, resection should be considered because of risk of later possible problems [2-6].

\section{CONCLUSION}

Heterotopic pancreas which is uncommon may be responsible for gastrointestinal symptoms and endoscopic appearance may be often confused with neoplasm (benign and malignant).

\section{REFERENCE}

1. Armstrong, C. P., King, P. M., Dixon, J. M., \& Macleod, I. B. (1981). The clinical significance of heterotopic pancreas in the gastrointestinal tract. British Journal of Surgery, 68(6), 384-387.

2. De Friend, D. J., Saa-Gandi, F. W., Humphrey, C. S., \& Foster, D. N. (1991). Symptomatic pancreatic heterotopia treated by local excision. Gut, 32(3), 332-333.

3. Rubbia-Brandt, L., Huber, O., Hadengue, A., \& Frossard, J. L. (2004). An unusual case of gastric heterotopic pancreas. Journal of the Pancreas, 5(6), 484-7.

4. Eisenberger, C. F., Gocht, A., Knoefel, W. T., Busch, C. B., Peiper, M., Kutup, A., \& Izbicki, J. R. (2004). Heterotopic pancreas--clinical presentation and pathology with review of the literature. Hepato-gastroenterology, 51(57), 854 858.

5. Galvez-Valdovinos, R., Mendoza-Rodriguez, A., Coronado-Perez, J. H., Santillan, E. M., \& FunesRodriguez, F. (2006). Laparoscopic treatment of heterotopic pancreas in the prepyloric region. Journal of minimal access surgery, 2(4), 224.

6. Margolin, D. J. (2008). Endoscopy-assisted laparoscopic resection of gastric heterotopic pancreas. The American Surgeon, 74(9), 829-831. 